\title{
Microelectronic Wire Bonding with Insulated Au Wire: Effects of Process Parameters on Insulation Removal and Crescent Bonding
}

\author{
Jaesik Lee $^{1}$, Michael Mayer ${ }^{1}$, Norman Zhou ${ }^{1}$ and John Persic ${ }^{2}$ \\ ${ }^{1}$ Microjoining Lab, Centre for Advanced Materials Joining, Department of Mechanical and Mechatronics Engineering, \\ University of Waterloo, Waterloo, Canada \\ ${ }^{2}$ Microbonds Inc., Markham, Canada
}

The characteristics of the crescent bond process with insulated $\mathrm{Au}$ wire are investigated. Au wire with a sub-micron thick insulation coating is bonded on standard Ag plated leadframe diepads at $493 \mathrm{~K}$. The wire loops are oriented perpendicular to the ultrasonic horn. The pull force obtained with a basic bonding process of insulated Au wire and bare Au wire are optimized by iteration and compared. Subsequently, the process is modified for the application with insulated wire. To increase the pull force an insulation layer removing stage (cleaning stage) is inserted before the bonding stage. The cleaning stage consists of a scratching motion (shift) toward to the ball bond in combination with ultrasound. The pull force obtained in this way with the insulated wire is $90.1 \pm 7.9 \mathrm{mN}$ which is $2.4 \pm 2.0 \mathrm{mN}$ larger than that obtained with bare Au wire. [doi:10.2320/matertrans.MRA2008087]

(Received March 7, 2008; Accepted June 30, 2008; Published September 25, 2008)

Keywords: thermosonic, wire bonding, crescent bond, insulation layer

\section{Introduction}

As the semiconductor industry moves to shrinking die and pad pitch and 3-D packaging solutions ${ }^{1)}$ to meet the demands of low cost, higher I/O interconnection, and more electrical power for electronic devices, new and disruptive technologies are needed to meet the many challenges.

The challenge associated with thinner or longer wire is to prevent wire sweep and shorts which can occur during molding of wire bond packages. ${ }^{2-5)}$ In the molding process the forces caused by resin flow can displace the fine wire loops. This flow-induced deformation of the wire loop can result in wire shorting and the failure of the device.

Insulated bonding wire is a disruptive technology that is gaining more and more momentum. ${ }^{1)}$ Its insulating capability improves the flexibility of wire bond design as the wires can touch each other without impairing the device specifications. Longer wires, sagging wires, crossing wires, lower loops, wire sway, and wire sweep are no roadblocks to production anymore and can be acceptable if insulated wire is used.

During the ball formation, the insulation layer is readily removed by the electrical flame-off (EFO) process. Proper parameter settings result in free-air ball (FAB) properties comparable to those obtained with bare Au wire. The ball bondability and bond reliability obtained with the insulated wire FABs are very similar to those obtained with bare $\mathrm{Au}$ wire FABs. ${ }^{6}$ ) However, the crescent bonding behavior of insulated wire is different from that of bare Au wire. This study is focused on the crescent bond (2nd bond, or wedge bond) with insulated wire and its optimization using a cleaning stage (CS) for bonding on Ag plated leadframes.

\section{Experimental}

Standard $\mathrm{Au}$ wire and insulated $\mathrm{Au}$ wire available from Microbonds, Markham, Canada, $\left(\mathrm{X}-\mathrm{Wire}^{\mathrm{TM}}\right)$, all with $25 \mu \mathrm{m}$ diameter, are used for bonding on standard PLCC 44 leadframe diepads with $8 \mu \mathrm{m}$ thick Ag metallization (sub-

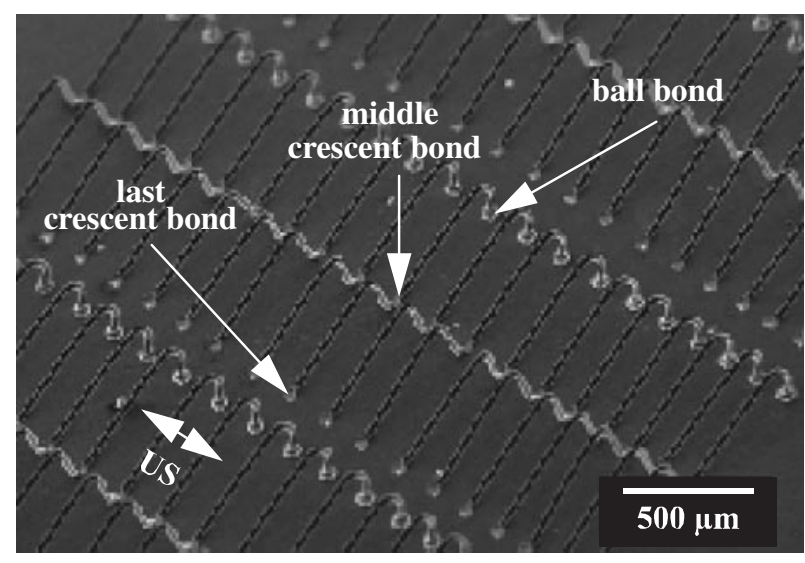

Fig. 1 BWW bonds used to optimize $P F$ of middle crescent bonds.

strate). Tip, chamfer, and hole diameters of the capillary used are $100 \mu \mathrm{m}, 51 \mu \mathrm{m}$, and $35 \mu \mathrm{m}$, respectively. The ultrasonic frequency is $128 \mathrm{kHz}$.

The special "ball-wedge-wedge" (BWW) function of an ESEC 3088 wire bonder is used to produce double wire loops for this study. These loops have a middle bond between the first and the last bond as shown in Fig. 1 and illustrated in Figs. 2(a), (b), and (c). The BWW function does not break the wire after a first wire loop but adds a second wire loop before generating a new tail. The second bond of the first loop is also the first bond of the second loop. The second looping trajectory does not have a reverse motion in order not to weaken or break the middle bond. Therefore, the second loop turns out to be flatter than the first. The first and last bonds are made with parameters optimized for strength and always stick well. The middle bond is made with varying parameters for this study and sometimes does not stick ("lift-off") when optimized parameters are not used. However, the second loop can be formed even if the middle bond is weak or lifts off, still allowing for continuous BWW bonding without the need to attend to the machine. The use of the BWW middle 
(a)

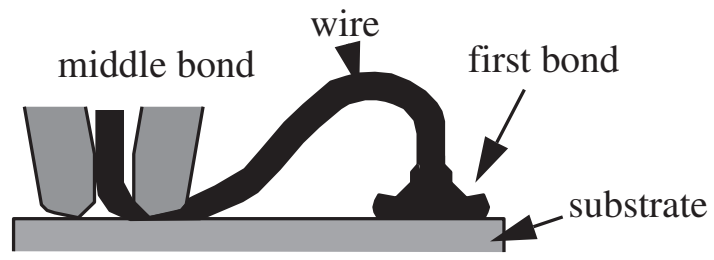

(b) last bond

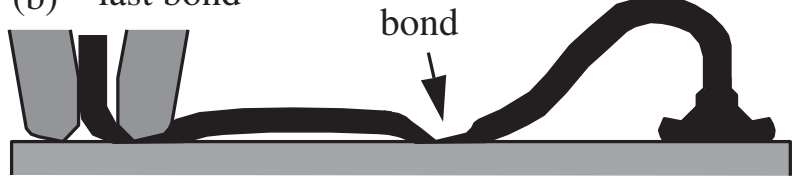

(c)

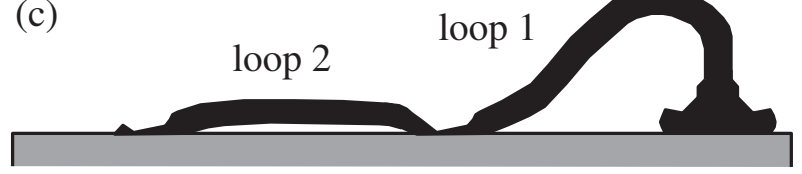

Fig. 2 Concept of BWW bonding. (a) first (ball) and middle bond (crescent/wedge), (b) last bond (crescent/wedge), (c) final two loops.

Table 1 Bonding parameter variations used for crescent bond $P F$ optimization.

\begin{tabular}{ccrc}
\hline & First Wire & Step & Last Wire \\
\hline$U S(\%)$ & 5 & 5 & 95 \\
\hline$I F(\mathrm{mN})$ & 300 & 100 & 2000 \\
\hline$B F(\mathrm{mN})$ & 300 & 50 & 1000 \\
\hline
\end{tabular}

bond as test bond therefore greatly accelerates the data collection for this study.

Crescent bonds are made with bare and insulated wires using a basic and a modified process. For simplicity, all wire loops are directed perpendicular to the ultrasonic direction in this study. The quality of the bonds is determined using the pull force $(P F)$ as measured by the standard pull test. During the test, the pull speed is $200 \mu \mathrm{m} \cdot \mathrm{s}^{-1}$. The hook location is at about $30 \%$ of the distance closer to the crescent bond of the first loop.

To maximize the $P F$ of the middle bonds, they are made with variations of impact force $(I F)$, bonding force $(B F)$, and ultrasound $(U S)$, as shown in Table 1 while bonding time $(B T)$ and bonding temperature (T) are fixed to $25 \mathrm{~ms}$, and $493 \mathrm{~K}$, respectively. The unit "\%" is used for the US parameter, where $1 \%$ is equivalent to a peak to peak ultrasonic vibration amplitude of $26.6 \mathrm{~nm}$ measured at the center of the transducer tip or $8.7 \mathrm{~mA}$ peak-to-peak current delivered to this transducer sample. Estimated values of ultrasound power generated by the stack of piezo-ceramics on the transducer are 16,71 , and $203 \mathrm{~mW}$ for ultrasound parameters 15,30 , and $50 \%$, respectively.

Bonds and pull tests are made in an iterative way to find the optimized parameters $I F, B F$, and $U S$, yielding the maximum crescent $P F{ }^{7)}$ Figure 3 shows an example of middle bond used for iteration optimization. It consists of a crescent bond and a tail bond.

Subsequently, confirmation runs are carried out using the optimized parameters. A confirmation run consists of 100

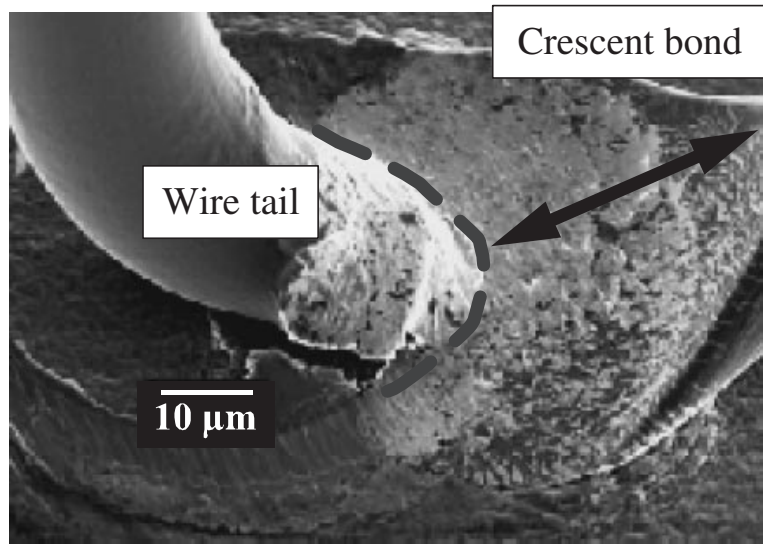

Fig. 3 Middle bond made with BWW.

BWW double loops bonded on five diepads randomly chosen from five different leadframes to eliminate the effects of the diepad and leadframe variations. The confirmation run sample size is larger than that used during the optimization runs and therefore gives more significant and usually different statistical results. Differences are due to process drifts that can be significant over minutes and hours and are commonly occurring in wire bonding.

\section{Results and Discussions}

\subsection{Basic bonding process}

The basic process is characterized by the shape of its parameter profiles as illustrated in Fig. 4. The machine settings are impact force $(I F)$, bonding force $(B F)$, ultrasound $(U S)$, ultrasound time $(B T)$, and shift distance. The starting parameters for the crescent bond $P F$ optimization by iteration $^{7)}$ are $I F=750 \mathrm{mN}$ and $B F=350 \mathrm{mN}$ with insulated wire. After the optimization of the $U S$, the $I F$ and the $B F$ are optimized in the same way, concluding the first iteration. With the third iteration no significant $P F$ improvement is found in this case.

The iteration results are summarized in Table 2. The maximum $P F$ is obtained with $U S, I F$, and $B F$ of $15 \%$, $500 \mathrm{mN}$, and $500 \mathrm{mN}$, respectively. The iteration results obtained with bare wire are listed in Table 3 for comparison. The optimized parameters in that case are similar to those shown in Table 2 except for $10 \%$ lower $I F$ and $B F$ values.

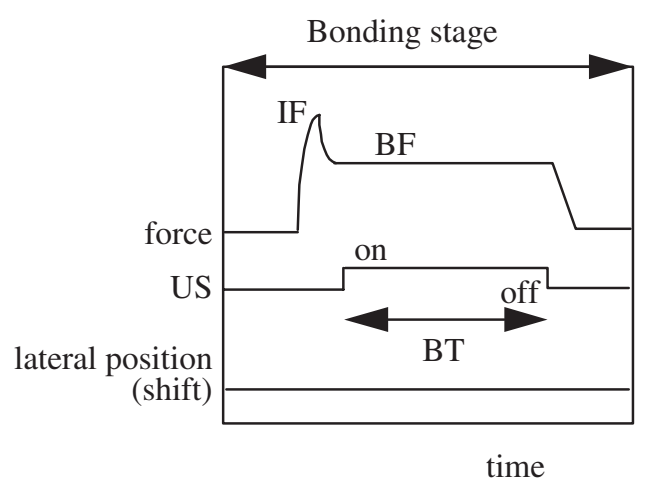

Fig. 4 Basic process type. Illustration of crescent bond parameter profiles. Signals not to scale. 
Table 2 Optimization of crescent bond $P F$ of insulated Au wire process.

\begin{tabular}{cccccc}
\hline $\begin{array}{c}\text { Iteration } \\
\#\end{array}$ & $\begin{array}{c}U S \\
(\%)\end{array}$ & $\begin{array}{c}I F \\
(\mathrm{mN})\end{array}$ & $\begin{array}{c}B F \\
(\mathrm{mN})\end{array}$ & $\begin{array}{c}\text { Av. } P F \\
(\mathrm{mN})\end{array}$ & $\begin{array}{c}\sigma \\
(\mathrm{mN})\end{array}$ \\
\hline 1 & 30 & 700 & 400 & 61.6 & 9.51 \\
\hline 2 & 15 & 500 & 500 & 65.16 & 7.40 \\
\hline 3 & 15 & 500 & 500 & 64.74 & 7.30 \\
\hline
\end{tabular}

Table 3 Optimization of crescent bond $P F$ of bare Au wire process.

\begin{tabular}{cccccc}
\hline $\begin{array}{c}\text { Iteration } \\
\#\end{array}$ & $\begin{array}{c}U S \\
(\%)\end{array}$ & $\begin{array}{c}I F \\
(\mathrm{mN})\end{array}$ & $\begin{array}{c}B F \\
(\mathrm{mN})\end{array}$ & $\begin{array}{c}\text { Av. } P F \\
(\mathrm{mN})\end{array}$ & $\begin{array}{c}\sigma \\
(\mathrm{mN})\end{array}$ \\
\hline 1 & 13 & 450 & 400 & 85.58 & 4.81 \\
\hline 2 & 15 & 450 & 450 & 86.16 & 6.02 \\
\hline 3 & 15 & 450 & 450 & 85.83 & 8.38 \\
\hline
\end{tabular}

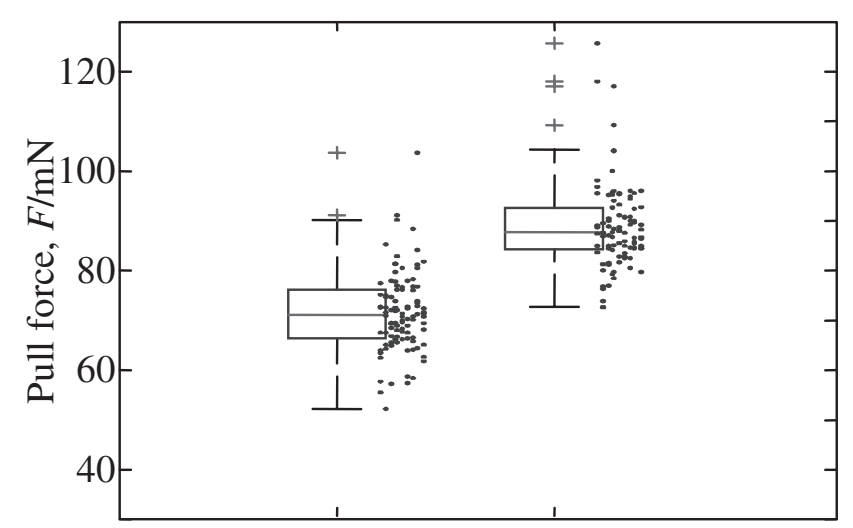

Insulated $\mathrm{Au}$ Wire Bare $\mathrm{Au}$ Wire Basic Process

Fig. 5 Comparison of optimized pull force of crescent bonds with insulated $\mathrm{Au}$ wire and bare $\mathrm{Au}$ wire using basic bonding procedure.

The results of $P F$ confirmation runs with insulated and bare Au wire are shown in Fig. 5. The $P F$ differs from those obtained in previous optimization runs possibly due to the equipment having been run in during a longer time during confirmation.

The average $P F$ obtained with the insulated Au wire is $71.5 \pm 8.0 \mathrm{mN}$ which is $81 \%$ of that obtained with bare $\mathrm{Au}$ wire, $87.7 \pm 6.2 \mathrm{mN}$. The $P F$ of insulated Au wire is affected by the insulation material remaining at the interface after bonding as shown in Fig. 6. The figure shows a bond footprint observed after the bonded wire is peeled off with a tweezer. The black areas are insulation material that remained on the substrate. Such residues reduce the total metallic bonded area resulting in a smaller $P F$ value.

As $P F$ with insulated wire comparable with that of bare wire is not achieved with this basic process type, a modified process type improving the $P F$ with insulated wire is studied in the next section.

\subsection{Bonding process with cleaning stage}

A cleaning stage (CS) is inserted before the basic bonding stage. The parameter profiles of this "CS process" are illustrated in Fig. 7. Ultrasonic friction can clean a bonding

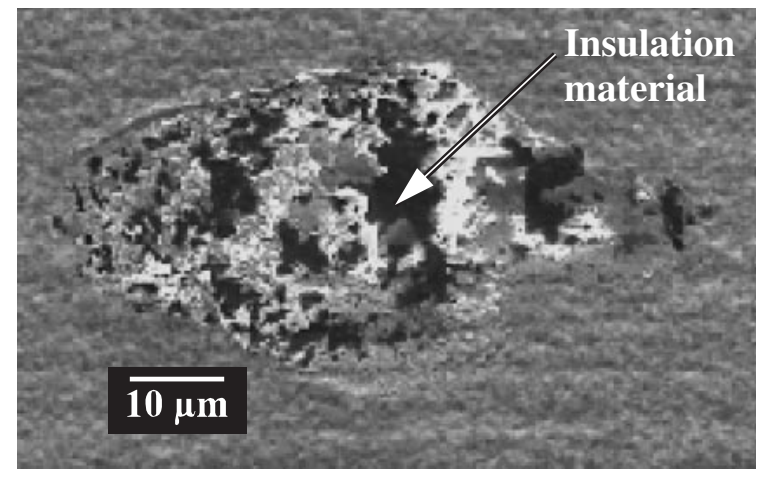

Fig. 6 SEM of fracture surface after peeling off crescent bond. $U S=15 \%$, $I F=500 \mathrm{mN}, B F=250 \mathrm{mN}$.

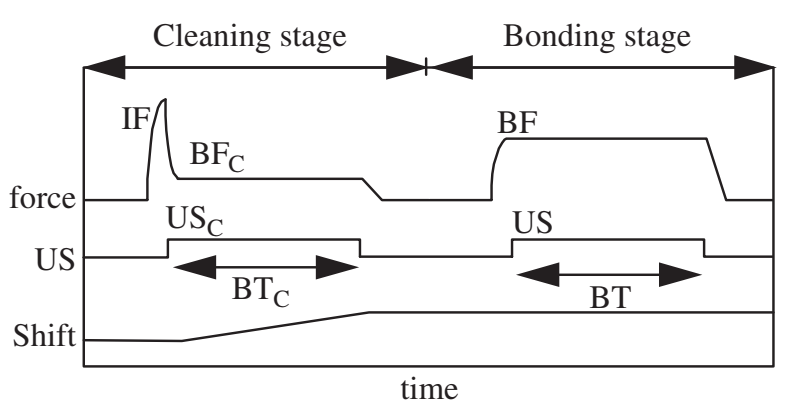

Fig. 7 Modified process type with cleaning stage (CS process). Illustration of crescent bond parameter profiles. Signals not to scale.

interface from oxide layers and various other impurities during a thermosonic wire bonding process. ${ }^{8-10)}$ The CS process relies on ultrasonic friction to clean away the insulation and improve the $P F$ of the bond.

First, an $I F$ is applied to produce an initial deformation of the wire. It is followed by the CS in which a shift combined with ultrasonic friction is applied to remove the insulation layer. The shift is directed towards the ball bond. The maximum shift distance offered by the equipment is $20 \mu \mathrm{m}$. This value is chosen for all trials of this study. The CS is followed by a bonding stage with the previously optimized process parameters $B F$ and $U S$. The process parameters during cleaning are the force $B F_{\mathrm{C}}$, ultrasound $U S_{\mathrm{C}}$, ultrasound duration $B T_{\mathrm{C}}$, and shift distance. These parameters are chosen from a "non-stick window" in order to avoid any sticking or wire cut and so to facilitate the shifting motion and avoid premature tail breaking. Non-stick windows for various $I F$ values are experimentally determined and shown in Fig. 8.

The efficiency of the CS is investigated by measuring the amount of insulation layer removal. For this, test middle bonds are produced without bonding stage and are rolled over with the pull hook of the commercial pull tester as illustrated in Figs. 9(a) and (b). The result of this sample preparation procedure is shown by the optical micrograph in Fig. 10. While the middle bond is already loose, the last bond is broken or peeled off during this procedure.

\subsection{Effect of $I F / U S$ on insulation layer removal}

In the basic parametrical study reported in this section, $I F$ and $U S_{\mathrm{C}}$ values are varied while $B F_{\mathrm{C}}=50 \mathrm{mN}$, 


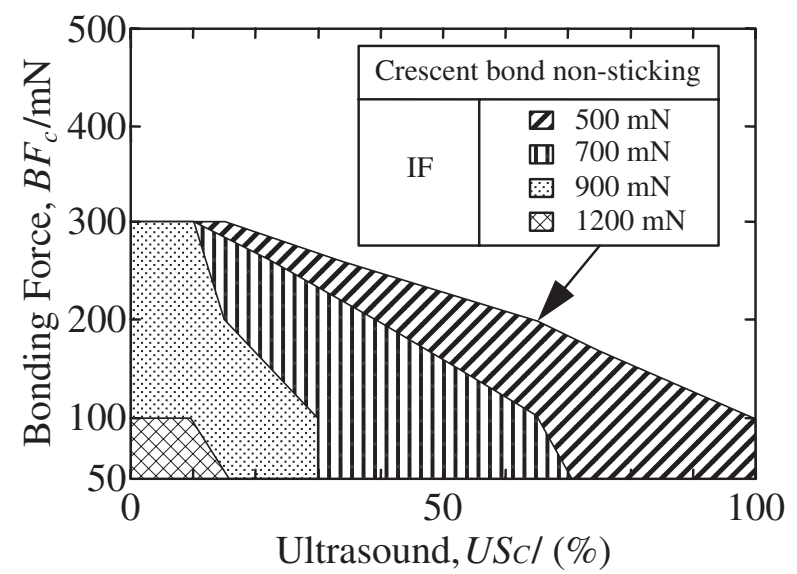

Fig. 8 Crescent bond non-sticking parameter regions (windows) for various $I F$. Non-stick windows obtained with higher $I F$ contain those obtained with lower $I F$.

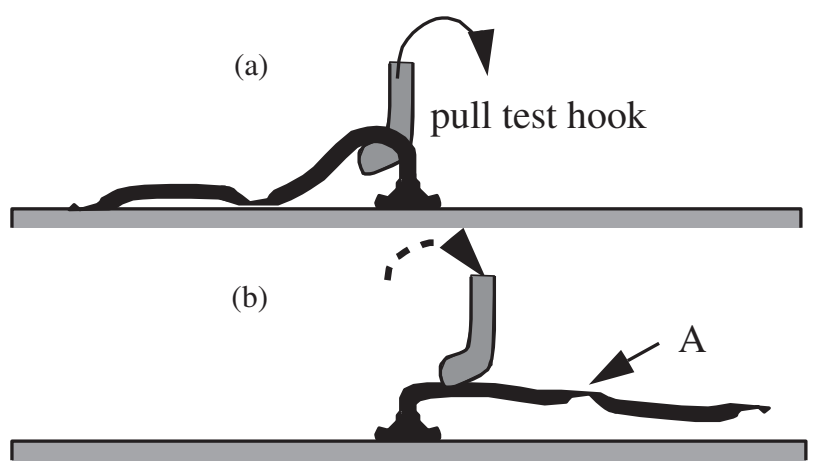

Fig. 9 "Rolling over" of BWW loops. (a) hook placed under first loop. (b) final position after breaking (middle and) last bond and subsequent bending. Bond interface (contact area) of middle bond (A) exposed.

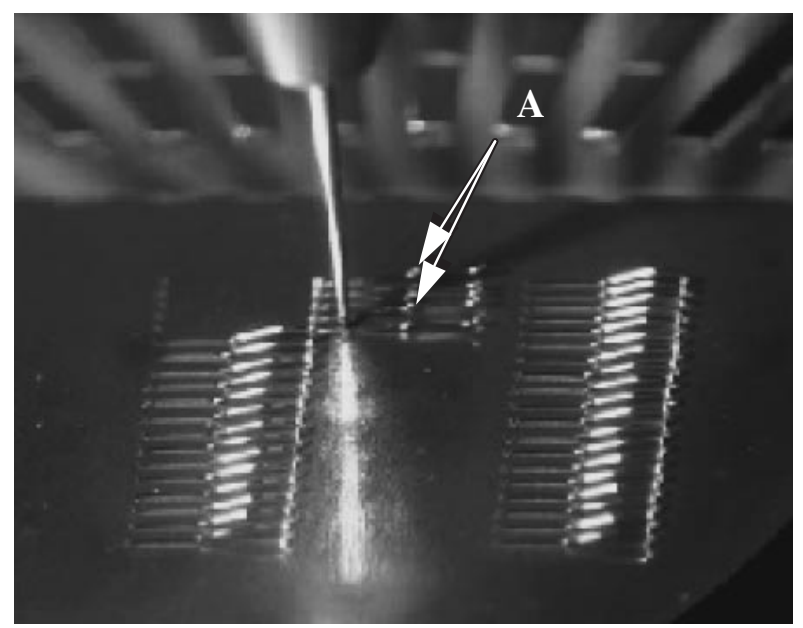

Fig. 10 Rolling over method to prepare samples to investigate contact area A of middle crescent bonds.

$B T_{\mathrm{C}}=25 \mathrm{~ms}$, and shift $=20 \mu \mathrm{m}$. To allow for a clear visual characterization of the insulation removal in these tests, no bonding stage is used after the CS. The middle bonds lift off and their wire contact areas are readily visible after rolling over the loops.
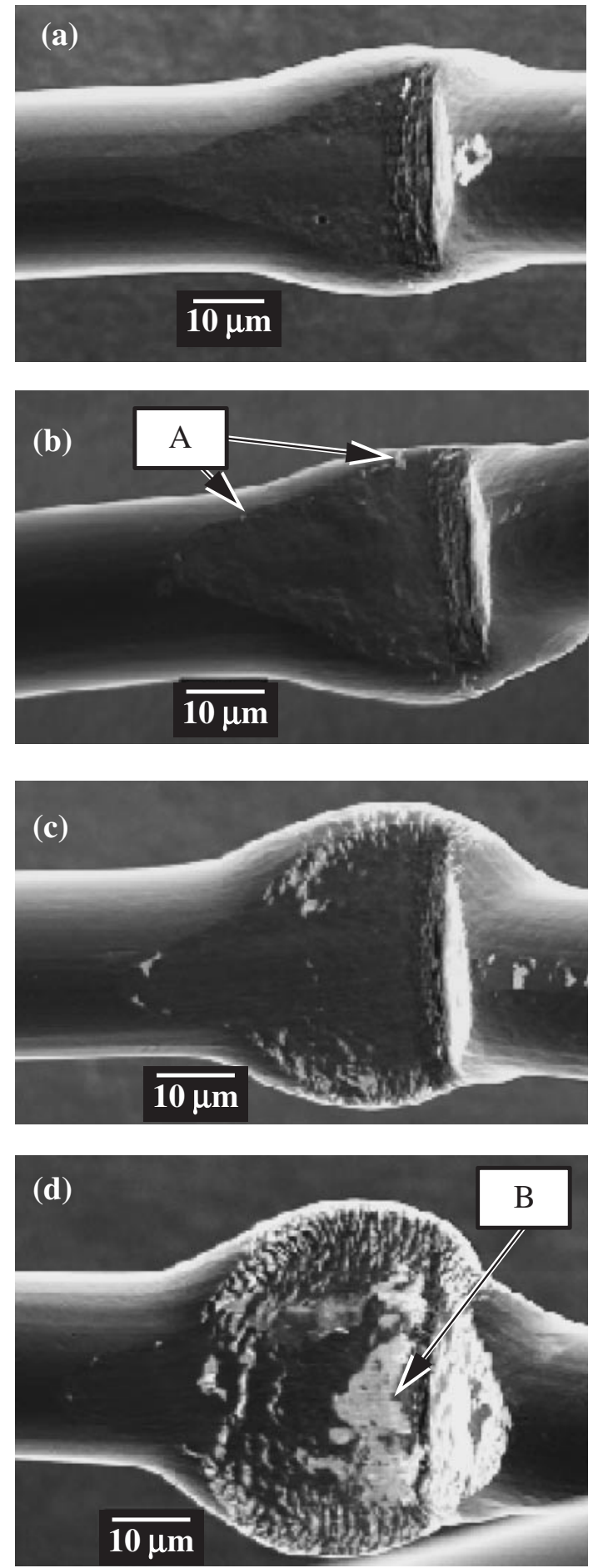

Fig. 11 SEM images of contact area of wires deformed with $I F$ (a) $500 \mathrm{mN}$, (b) $700 \mathrm{mN}$, (c) $800 \mathrm{mN}$, (d) $1200 \mathrm{mN} \cdot U S_{\mathrm{C}}=0 \%, B F_{\mathrm{C}}=$ $50 \mathrm{mN}, B T_{\mathrm{C}}=25 \mathrm{~ms}, T=220^{\circ} \mathrm{C}$, shift $=0 \mu \mathrm{m}$. No bonding stage.

The effects of $I F$ values of $500 \mathrm{mN}, 700 \mathrm{mN}, 800 \mathrm{mN}$, and $1200 \mathrm{mN}$ on the insulation layer removal are shown in Figs. 11(a), (b), (c), and (d), respectively. With the lowest values, $I F=500 \mathrm{mN}$ [Fig. 11(a)], plastic deformation of the crescent bond but no removal of the insulation layer is observed. With $I F=700 \mathrm{mN}$ as shown in Fig. 11(b), limited insulation layer removal indicated by white areas (letter A) is observed at the periphery of the bottom of the crescent bond. This is consistent with the amount of 


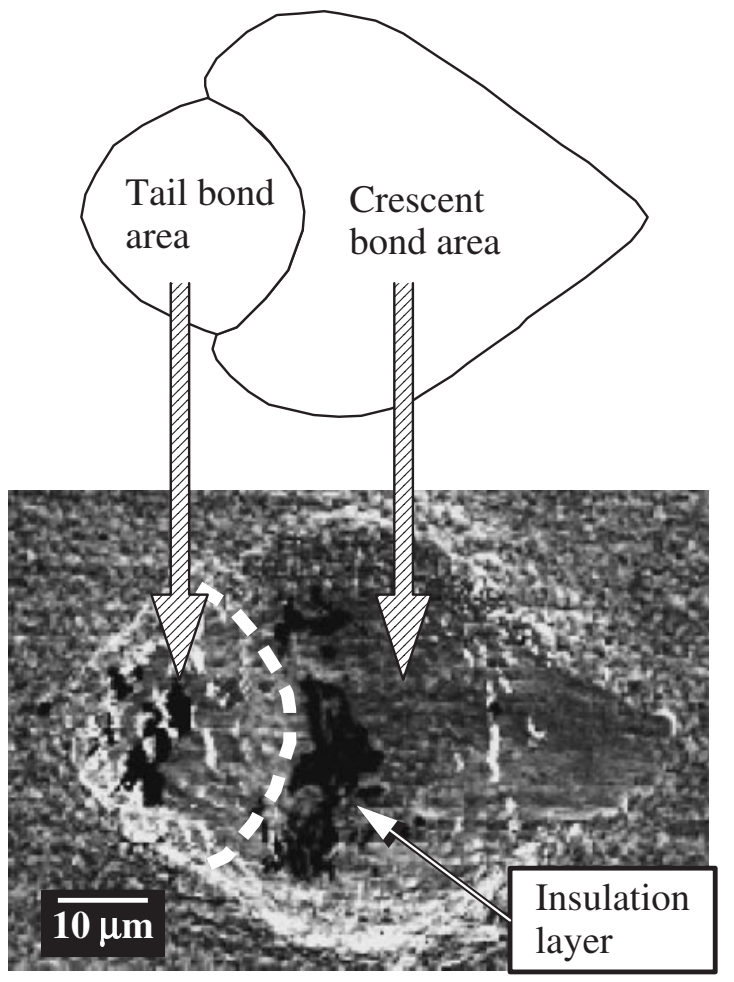

Fig. 12 SEM image of primary bonding site. Insulation layer transferred to substrate.

plastic deformation and contact pressure being largest at the periphery. ${ }^{11)}$

With $I F=800 \mathrm{mN}$, more insulation is removed towards the center of the contact zone as shown in Fig. 11(c). The more wire plastically deforms caused by the increased $I F$, the more insulation cracks. The possible reason is the difference in ductility between the Au wire and the insulation material. With $I F=1200 \mathrm{mN}$, an additional type of the insulation layer removal in the center is observed as indicated by B in Fig. 11(d). The insulation layer is partly detached from the wire and is left on the diepad as shown in Fig. 12. The insulation parts are found both on the tail and crescent bond area.

The effects of $U S_{\mathrm{C}}$ on insulation removal of processes with $I F \mathrm{~s}$ of $500 \mathrm{mN}$ and $1200 \mathrm{mN}$ are studied. The bottoms of the deformed wires observed with $I F$ of $500 \mathrm{mN}$ and $U S_{\mathrm{C}}$ of $0 \%$, $15 \%$, and 50\% are shown in Figs. 11(a), 13(a), and 13(b), respectively. No insulation layer removal is observed with $U S_{\mathrm{C}}$ of $0 \%$. As $U S_{\mathrm{C}}$ is increased to a moderate $15 \%$, about $38 \%$ of insulation layer is removed at the contact zone periphery. About $75 \%$ of insulation layer is removed with $U S_{\mathrm{C}}$ of $50 \%$ everywhere on the contact zone.

With $U S_{\mathrm{C}}$ of $50 \%$ a major portion of the interfacial insulation layer is transferred to the substrate as shown in Fig. 14. With application of the shift of $20 \mu \mathrm{m}$ toward to the ball as described in Fig. 7, a insulation removed wire (bare $\mathrm{Au}$ wire) portion of the insulated wire is contacted with a fresh substrate. During the bonding stage a bond is made between the fresh bare Au wire and the substrate.

Comparing Fig. 15(a) with Fig. 11(d), it is obvious that the insulation layer is mostly broken by high $I F$ at the periphery which are the SEM images of the bottoms of samples made
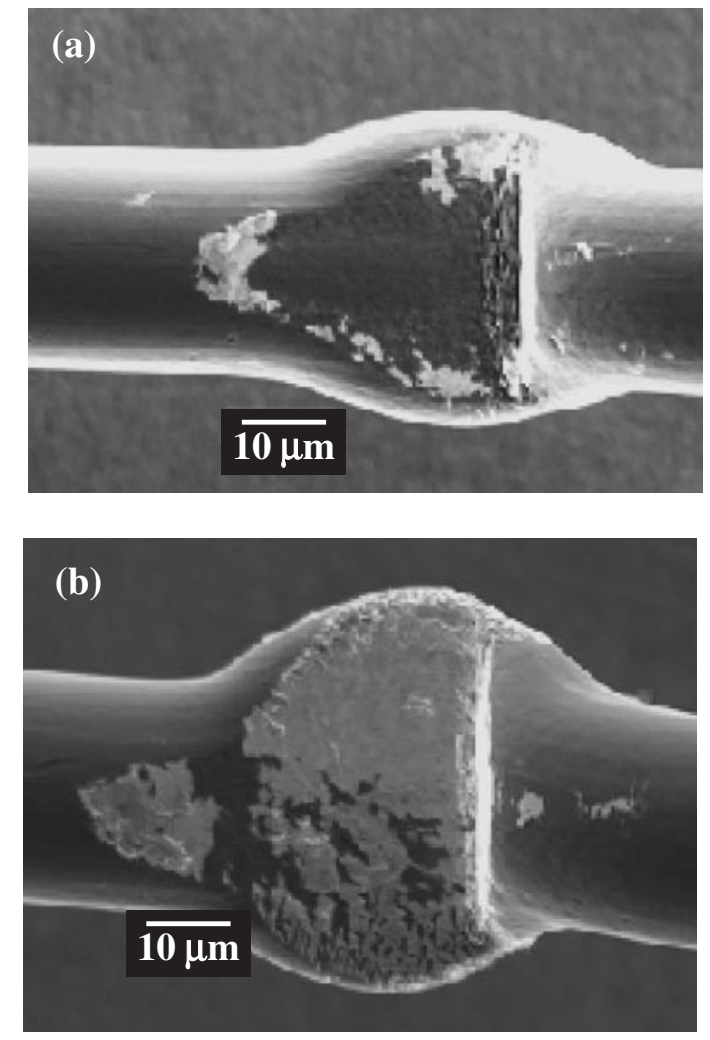

Fig. 13 SEM images of bottom of wire deformed with $I F=500 \mathrm{mN}, U S_{\mathrm{C}}$ (a) $15 \%$, (b) $50 \% \cdot B F_{\mathrm{C}}=50 \mathrm{mN}, B T_{\mathrm{C}}=25 \mathrm{~ms}, T=220^{\circ} \mathrm{C}$, shift $=$ $0 \mu \mathrm{m}$. No bonding stage.

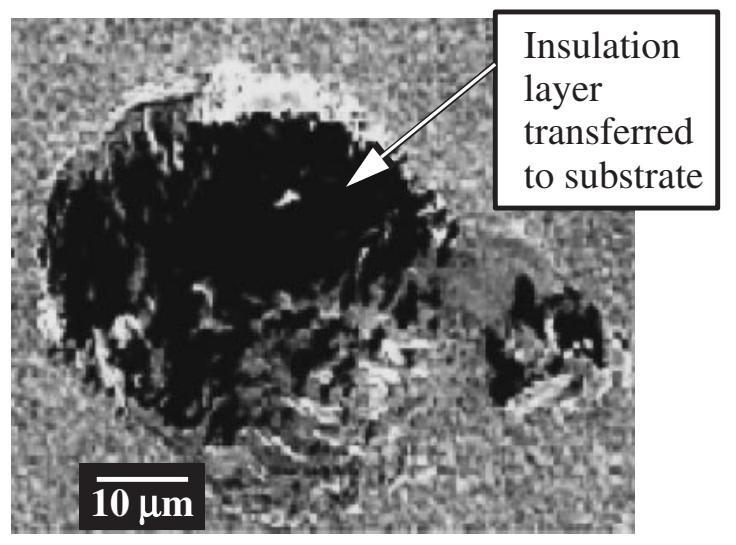

Fig. 14 SEM image of primary bonding site. $I F=500 \mathrm{mN}, U S_{\mathrm{C}}=50 \%$, $B F_{\mathrm{C}}=50 \mathrm{mN}, B T_{\mathrm{C}}=25 \mathrm{~ms}, T=220^{\circ} \mathrm{C}$, shift $=0 \mu \mathrm{m}$. No bonding stage.

with $I F$ of $1200 \mathrm{mN}$ and $U S_{\mathrm{C}}$ of $15 \%$ and $0 \%$, respectively. As $U S_{\mathrm{C}}$ is increased to $50 \%$, the ultrasonic vibration enlarges the wire deformation and frictional wear as shown in Fig. 15(b). However, only little insulation transfer to the substrate is observed after using high $I F$, as shown on the primary bond location in Fig. 16.

Even with the shift of $20 \mu \mathrm{m}$, the bare wire portion of the insulated wire which will be bonded to the fresh substrate during the bonding stage is limited which may reduce the $P F$. Furthermore, the portion of tail bond which is the second loop of the BWW is already broken with $U S_{\mathrm{C}}$ of $50 \%$ as shown in Fig. 15(b), which may result in premature tail breaking (short 

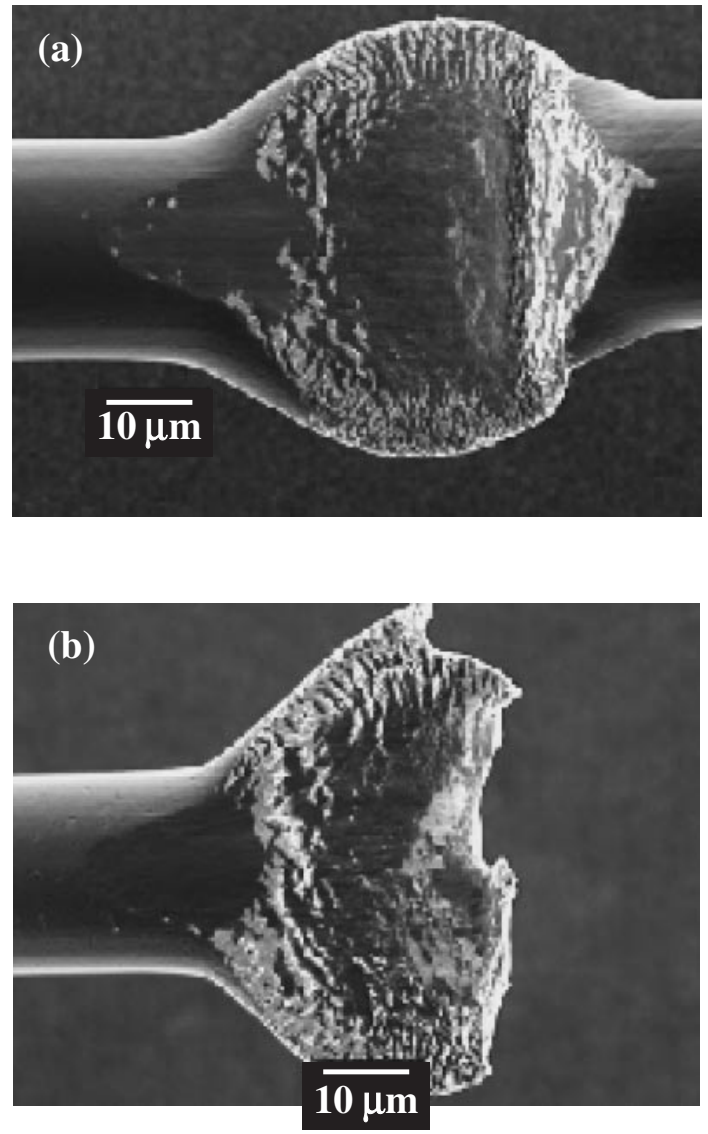

Fig. 15 SEM images of bottom of wire deformed with $I F=1200 \mathrm{mN}$ and $U S_{\mathrm{C}}$ (a) $15 \%$ and (b) $50 \%, B F_{\mathrm{C}}=50 \mathrm{mN}, B T_{\mathrm{C}}=25 \mathrm{~ms}, T=220^{\circ} \mathrm{C}$, shift $=0 \mu \mathrm{m}$. No bonding stage.

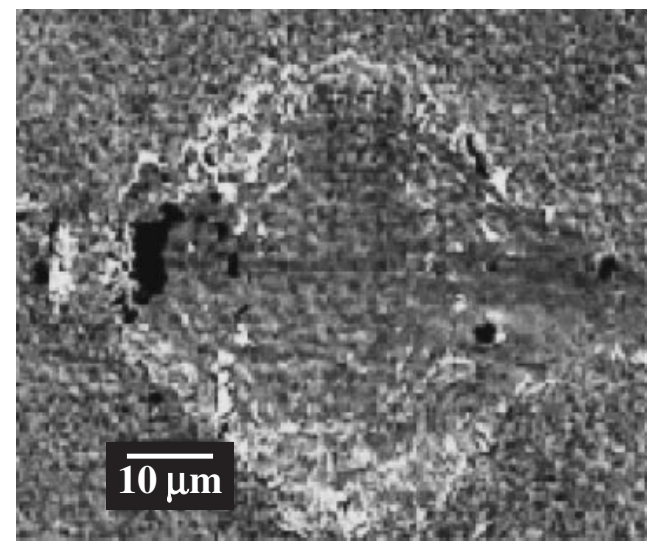

Fig. 16 SEM image of primary bonding site. $I F=900 \mathrm{mN}, U S_{\mathrm{C}}=50 \%$, $B F_{\mathrm{C}}=50 \mathrm{mN}, B T_{\mathrm{C}}=25 \mathrm{~ms}, T=220^{\circ} \mathrm{C}$, shift $=0 \mu \mathrm{m}$. No bonding stage.

tail) during bonding stage. It is concluded that $U S_{\mathrm{C}}$ of $50 \%$ with $I F$ of $500 \mathrm{mN}$ is suitable for CS process.

\subsection{PF with CS bonding process}

Results of confirmation runs with insulated $\mathrm{Au}$ wire with $\mathrm{CS}$ process and bare $\mathrm{Au}$ wire with the basic process are shown in Fig. 17. The parameters used are summarized in Table 4 . The average \pm standard deviation $P F$ obtained with insulated wire and the $\mathrm{CS}$ process is $90.11 \pm 7.87 \mathrm{mN}$, which

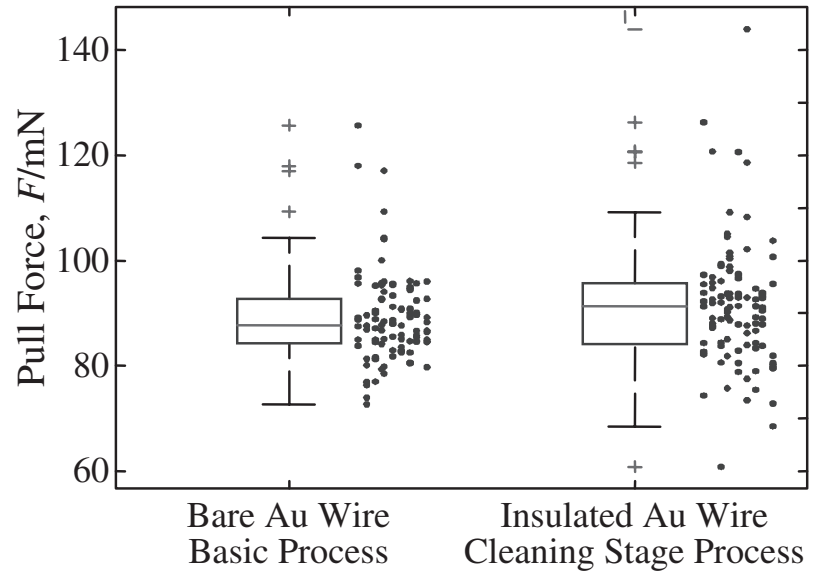

Fig. 17 Pull force comparison of crescent bonds with insulated Au wire bonded using basic process, and bare Au wire bonded using CS process.

Table 4 Process parameters for comparison experiment.

\begin{tabular}{|c|c|c|c|}
\hline & $\begin{array}{l}\text { Parameter } \\
\text { Name }\end{array}$ & $\begin{array}{l}\text { Value for } \\
\text { modified } \\
\text { process }\end{array}$ & $\begin{array}{c}\text { Value } \\
\text { for basic } \\
\text { process }\end{array}$ \\
\hline Impact & $I F$ & $500 \mathrm{mN}$ & $450 \mathrm{mN}$ \\
\hline \multirow{4}{*}{$\begin{array}{c}\text { Cleaning } \\
\text { Stage }\end{array}$} & $B F_{\mathrm{C}}$ & $50 \mathrm{mN}$ & \multirow{4}{*}{$\mathrm{n} / \mathrm{a}$} \\
\hline & $U S_{\mathrm{C}}$ & $50 \%$ & \\
\hline & $B T_{\mathrm{C}}$ & $25 \mathrm{~ms}$ & \\
\hline & Shift & $20 \mu \mathrm{m}$ & \\
\hline \multirow{3}{*}{$\begin{array}{c}\text { Bonding } \\
\text { Stage }\end{array}$} & $B F$ & $500 \mathrm{mN}$ & $450 \mathrm{mN}$ \\
\hline & $U S$ & $15 \%$ & $15 \%$ \\
\hline & $B T$ & $25 \mathrm{~ms}$ & $25 \mathrm{~ms}$ \\
\hline
\end{tabular}

is $2.4 \pm 2.0 \mathrm{mN}$ larger (95\% confidence level) than that obtained previously with bare wire and the basic process. The CS process $P F$ improvement compared to the basic process with insulated wire is $26 \% \pm 3 \%$.

Standard $P F$ quality can be obtained with the CS process and insulated wire. Future work is directed towards reducing the process time parameters $B T$ and $B T_{\mathrm{C}}$ and optimizing the shift distance. These parameters have not been optimized in this study.

\section{Conclusions}

(1) A basic bonding process with insulated Au wire yields around $20 \%$ lower average pull force than with bare wire.

(2) The insulation layer cracks where the underlying wire is heavily deformed. Such cracks occur e.g. at the contact zone periphery during initial deformation with a relatively high impact force of $1200 \mathrm{mN}$. However, such cracks are not necessary for efficient insulation removal.

(3) In a modified process with a cleaning stage, a combination of low impact force, ultrasound, and $20 \mu \mathrm{m}$ shift results in efficient insulated layer removal. The removed layer remains on the substrate surface, but out of newly bonded zone. 
(4) The cleaning stage before the basic bonding process improves the insulated Au wire pull force by about $26 \%$ slightly above the level obtained with bare wire and the basic process.

\section{Acknowledgement}

This work is supported by NSERC, AuTEK, and OCE (all from Canada).

\section{REFERENCES}

1) Assembly and Packaging, (ITRS update, 2006) pp. 1-19.

2) T. Yoshihara, M. Yuki, T. Hayashida and Y. Ohno: Electronics and Communications in Japan, Part 282 (1999) 59-67.
3) S. Ouimet and M. Paquet: IEEE Trans. Advanced Packag. 22 (1999) 123-128.

4) S. Han and K. K. Wang: IEEE Trans. Comp. Packag. Manuf. Technol. Part B 18 (1995) 744-750.

5) Y. F. Yao, B. Njoman, K. H. Chua and T. Y. Lin: Microelectron. Reliab. 45 (2005) 1222-1229.

6) C. Carr: Accelerated testing of Gold-Aluminium ball bonds, (Master thesis, University of Waterloo, Waterloo, Canada, 2005).

7) J. Lee, M. Mayer, Y. Zhou, S. J. Hong and S. M. Lee: Abstract in Proc IWJC-Korea, (2007) pp. 271.

8) H. Ji, M. Li, C. Wang, J. Guan and H. S. Bang: J. Mater. Process. Technol. 182 (2007) 202-206.

9) Y. N. Zhou, X. Li and N. J. Noolu: IEEE Trans. Comp. Packag. Technol. 28 (2005) 810-816.

10) M. Weissenfelt, P. Collander, E. Jarvinen and T. Laurinolli: Proc. 29th Electro. Comp. Conf. (1979) pp. 309-314.

11) Y. Ding, J. K. Kim and P. Tong: Mech. Mater. 38 (2006) 11-24. 